\title{
Análisis del retorno de la inversión (ROI) de la actividad en las redes sociales de las provincias andaluzas como destino turístico
}

\author{
Miguel Ángel Sánchez Jiménez*
}

Universidad de Cádiz (España)

\begin{abstract}
Resumen: Las actividades de innovación están muy presentes en el sector turístico, destacando el desarrollo tecnológico y la aparición de internet como principales avances que permitirán a estos sectores continuar con su gran importancia a nivel mundial. De esta manera, las posibilidades de comercialización y comunicación se han potenciado aún más con la aparición de los medios sociales, que facilitan la creación, edición e intercambio de contenido y que va a permitir a las empresas relacionarse de forma más directa e interactiva con los usuarios. En este escenario surge la necesidad del estudio de estas novedosas estrategias de marketing en el sector turístico. Así, en este estudio se ha analizado el ROI (retorno de la inversión) de las redes sociales oficiales de las 8 provincias andaluzas para su promoción turística, a través de la utilización de una serie de indicadores derivados del modelo PRGS que va a medir la presencia y la actividad de los destinos turísticos en las redes sociales. Estos indicadores se obtienen mediante la herramienta de análisis online Fanpage Karma. En los resultados destacan Facebook y Twitter como principales redes sociales utilizadas por las provincias andaluzas, sobre todo la primera, cuyo uso es generalizado, permitiendo un mayor engagement o interacción de los usuarios con el destino. En este sentido, Twitter destaca por la baja interacción de sus publicaciones, al contrario que Instagram que pese a no ser la más utilizada, destaca por ser la red social que cuenta con mayor interacción o engagement en sus publicaciones.
\end{abstract}

Palabras Clave: Turismo, Redes sociales, ROI, Engagement.

Analysis of the payback (ROI) thanks to activity on the social networks marketing Andalusian provinces as tourist destinations

Abstract: Innovation is constant in the sector of tourism, with technological developments and Internet opening up new horizons for tourist destinations. Sales and Marketing on social networks facilitate constant updating and creativity in exchange of content allowing the companies to enter into direct contact with their users without intermediaries. Thus, the social newtworks' possibilities require serious research. Here, we have analysed the ROI (return on investment) of the official social networks of the 8 Andalusian provincesfrom the perspective of tourism promotion, using the through the measurement indicators obtained from the online analysis tool, Fanpage Karma. In the results, Facebook and Twitter stand out as the main social networks used by the Andalusian provinces, especially the formert,that is given widespread use, allowing greater engagement and interaction of the users with the destination. In this sense, Twitter stands out for the low interactionproduced by itss publications, unlike Instagram, which although not widely used, is the social network that has greater interaction or engagement with its publications.

Keywords: Tourism, Social networks, ROI, Engagement.

\section{Introducción}

Con el creciente poder de los consumidores online y la mayor penetración de internet en todo el mundo, las comunidades online de marcas han formado una importante plataforma de comunicación

Personal docente e Investigador en la Universidad de Cádiz en el departamento de Marketing y Comunicación; E-mail:m iguelangel.sanchez@uca.es 
entre las empresas y los consumidores (Casaló et al., 2010). Como nuevas herramientas de comunicación de marketing se considera importante para las empresas gestionar estas comunidades online de manera efectiva con diversas actividades y acciones llevadas a cabo a través de las diferentes redes sociales (Mangold y Faulds, 2009).

Así, la aparición de internet ha generado un fuerte impacto en el sector turístico debido a las numerosas posibilidades que ofrece para la comunicación (Luque et al., 2007; Botella, 2010). A través de una conexión a la red cada usuario puede decidir qué destino elegir, cuál va a ser su destino final o qué actividades desea llevar a cabo en dicho lugar geográfico (Martínez et al., 2013), cambiando esta tendencia la forma de concebir los viajes, tanto para los turistas como para las empresas (Lincoln, 2009).

En esta realidad, en que los usuarios tenían acceso a una enorme cantidad de información, surge el fenómeno 2.0 y con él los medios sociales o social media, que busca un nuevo canal de comunicación que permita la interacción del usuario (Domínguez y Araujo, 2012). Según Martínez (2012), los medios sociales tratan de describir el fenómeno por el que los usuarios pasan a ser partícipes de la web y no espectadores que visualizan información. Los medios sociales han ofrecido al consumidor la oportunidad de compartir opiniones, recomendaciones y experiencias a través de comentarios, imágenes o videos con otros usuarios, que pueden ser leídos y comentados entre ellos. Esto ha llevado a que muchas empresas turísticas se hayan lanzado a probarlo y tengan la oportunidad tanto de analizar la información como de comunicarse con el consumidor, dando paso a la promoción de ventas con el objetivo de crear un mensaje centrado en el cliente.

Justificar el valor de la intervención de las empresas o marcas en los medios sociales y conocer cuál es la utilidad o los beneficios que proporciona el marketing en estos medios ha sido una prioridad a lo largo de los años. A medida que esta tendencia ha aumentado, los vendedores han tenido que tomar las decisiones correctas sobre los aspectos claves de los medios sociales y determinar cómo medir su eficacia a través del retorno de la inversión (ROI). Buscar y encontrar métricas para obtener el ROI se ha convertido en un objetivo para organizaciones y expertos en marketing (Kingma y Mcclure, 2015; McMullen, 2013). Según Powell et al. (2011) el futuro de los medios sociales y su capacidad de medir el ROI ha generado un gran debate en los últimos años, que ha ido en aumento a medida que las compañías han ido adoptando el uso de plataformas de medios sociales para comunicar sus productos. Aunque el cálculo de esta inversión puede ser una tarea compleja para la empresa, no realizarlo puede poner en peligro su capacidad para especificar los beneficios del negocio. De ahí que la necesidad de demostrar el ROI de una inversión en medios sociales sea cada vez más urgente. Por tanto, se considera de interés estudiar el papel que la función del marketing juega en los medios sociales a través del ROI, ya que se relaciona con la capacidad de los comerciantes para obtener un valor positivo a corto y largo plazo para la organización. Esto debe tenerse en cuenta en los medios sociales más populares como Facebook, Twitter o YouTube. (Tessler, 2013). Por las particularidades del sector turístico, éste se constituye como adecuado para la medición de sus acciones de marketing online o presencia en medios sociales, ya que la subjetividad que recorre todo el proceso turístico anima a incluir herramientas de medición que tengan en cuenta este hecho (Bonilla, 2013).

De esta manera, en este estudio se ha comprobado en qué redes sociales intervienen las principales provincias de Andalucía para promocionarse como destino turístico para, posteriormente, analizar el ROI de la actividad que realizan dichas redes sociales a través de la medición de una serie de indicadores de rendimiento mediante la herramienta de análisis online "Fanpage Karma".

\section{Marco teórico}

\subsection{Las nuevas tecnologías de la comunicación (TIC) y los medios sociales en el sector turístico}

Entre finales del siglo XX y principios del siglo XXI internet comienza a jugar un importante papel en el turismo como herramienta de promoción y comercialización, ofreciendo al sector gran facilidad en la modificación y actualización de la información (Galí et al., 2000). En una primera fase, ese proceso consistía básicamente en la creación de páginas webs y acuerdos con las agencias de viajes ya existentes en la red para la venta de sus servicios, de igual forma que hasta ese momento se hacía con las agencias de viajes convencionales.

Las TIC e internet han cambiado la manera en que se informa sobre el turismo (Buhalis y Law, 2008) y la forma en que las compañías y comunidades turísticas trabajan en el diseño y la comercialización de sus productos, del mismo modo en que se ha transformado la forma en que los turistas planifican, reservan y viven sus experiencias turísticas (Munar, 2012). Así, los avances tecnológicos y la introducción 
de nuevos métodos de comunicación han alterado significativamente el comportamiento del consumidor turístico. Internet se ha convertido en la primera opción del consumidor en la búsqueda de información sobre destinos turísticos y proveedores y se ha convertido en una herramienta importante para la comercialización de servicios turísticos (Law et al., 2014)

Ferrá y Cardona (2015) consideran que las TIC forman parte de la cultura actual y amplían las posibilidades de desarrollo social personal. Suele incluirse en el concepto TIC no solamente la informática y sus tecnologías asociadas, telemática y multimedia, sino también los medios de comunicación de todo tipo: los medios de comunicación social y los medios de comunicación interpersonales tradicionales con soporte tecnológico como el teléfono.

De esta forma surge el termino de turismo electrónico (e-tourism) que incluye el diseño, la implementación y la aplicación de las TIC y soluciones de comercio electrónico en la industria del turismo, el análisis del impacto de los procesos económicos y técnicos, así como las estructuras de mercado de todos los actores involucrados en las experiencias de los viajeros (Werthner et al., 2015).

El turismo electrónico se ha potencializado con la web 2.0 puesto que ha facilitado el uso de los medios sociales (Perdomo Castellano et al., 2014). Éstos implican el uso de plataformas de comunicación en línea donde el contenido es creado por los propios usuarios facilitando aspectos como edición, publicación e intercambio de información. Entre ellas destacan blogs, redes sociales, sistemas de recomendación, integración de contenidos, audio y video, utilizándose en el proceso de anticipación, experiencia y recreación del viaje turístico (Caro et al, 2015).

Durante la última década, los investigadores han mostrado un creciente interés en el papel de los medios sociales en el campo del turismo. La literatura sugiere que las plataformas de los medios sociales desempeñan un papel importante en muchos asuntos del turismo, especialmente el comportamiento del consumidor (búsqueda de información y toma de decisiones), marketing y comunicación, interacción de los turistas y gestión de procesos comerciales (Bilgihan et al., 2016; Law et al., 2014; Leung et al., 2013; Gretzel y Yoo, 2013).

Según Xiang y Gretzel (2010), la web 2.0 ha sido el principio de dos tendencias fundamentales: la aparición de los medios sociales y el aumento en la cantidad de información que se puede encontrar. Estos son dos elementos que se encuentran estrechamente vinculados, ya que el aumento de la información y los elementos turísticos en la red se han encontrado con la información producida por los usuarios como consecuencia del surgimiento de la web 2.0 y de los nuevos elementos sociales relacionados con este avance (Sotiriadis y Zyl, 2013); y que se combinan con los datos y contenidos extras que tienen origen en las compañías y empresas encargadas de gestionar los destinos turísticos (Hudson y Thal, 2013).

Ante este panorama, la información que se comparte en los medios sociales se reconoce como un punto fundamental de información que puede facilitar la programación de los viajes o inclusive puede influenciar en la toma de decisiones de un potencial turista (Kang y Schuett, 2013). Dichos turistas potenciales suelen verse influenciados por las experiencias y opiniones de terceros a la hora de tomar decisiones en lo que respecta a su viaje (Zeng y Gerritsen, 2014). Por razones como las expuestas anteriormente, la web 2.0 y los medios sociales han transformado la manera en que los usuarios programan y compran sus viajes. De esta forma, la web 2.0 ha quitado cierta importancia a la web de antaño, ya que la información, hablando desde un punto de vista cuantitativo y cualitativo, ha mejorado considerablemente, debido a que los propios usuarios amplían dicha información con sus propias experiencias.

Las características propias del sector turístico, hacen que sea mayor su repercusión en los medios sociales. El sector turístico, como cualquier sector servicios, vende productos intangibles que se caracterizan por ser inseparables, perecederos y heterogéneos (Sirakaya y Woodsideb, 2005), de ahí que el proceso de comunicación sea un elemento vital en la oferta (Sigala, 2007). Por esta razón, el uso de los medios sociales ha permitido nuevas posibilidades de comunicación y ha proporcionado un impacto sustancial en la demanda y la oferta turística (Martínez et al., 2013).

De hecho, los medios sociales están cambiando la forma en que el turista consume y contribuye a la creación de información, suponiendo una alteración radical en la manera en que la información se difunde (Buhalis y Law, 2008; Senecal y Nantel, 2004; Xiang y Gretzel, 2010), de esta forma los consumidores obtienen información a través de los medios sociales para realizar su viaje (destinos, acomodación, restaurantes, tours y atracciones) (Chung y Buhalis, 2008; Ruzic y Bilos, 2010; Thevenot, 2007). Además, las experiencias relacionadas con el turismo no pueden ser valoradas hasta que se consumen, puesto que son intangibles, de ahí que los medios sociales, con las recomendaciones personales de los usuarios y de personas cercanas, sean muy influyentes a la hora de tomar una decisión sobre la elección turística (Buhalis, 1998; Wöber y Gretzel, 2000; Litvin, et al., 2008). 
Hernández et al. (2012) destacan que la imagen y la reputación online en el ámbito del turismo en general es de vital importancia, dado que los productos que se ofrecen en este ámbito son intangibles y no pueden evaluarse antes de su consumo, por lo que la experiencia de otros usuarios resulta ser de gran valor a la hora de tomar una decisión de compra. Así, cabe destacar el estudio realizado por López (2010) acerca de la reputación online en el sector turístico. En el artículo se aclara que la reputación online toma relevancia en los medios sociales, donde el usuario se convierte en creador de contenidos que, a su vez, pueden influir en otros clientes. Blogs, "reviews" (opiniones), valoraciones, foros, etc. son elementos habituales de este proceso de reputación online. Las claves de estos medios sociales son: colaboración, intercambio y contenido generado por los usuarios. Además, esas opiniones de los usuarios se pueden convertir en prescripciones, marketing viral, factor decisivo de compra, incremento del valor del contenido de nuestra web, herramienta de "feedback", etc., sin duda, componentes de gran valía para la construcción y potenciación de la reputación online positiva. Esto cobra especial relevancia en el sector turístico donde se empieza a notar la popularidad de webs que permiten estos comentarios, como por ejemplo Tripadvisor, entre otras, que consiguen crear un estado de opinión positivo o negativo. El artículo explica que la reputación online por parte del sector turístico debe gestionarse de manera que lleve a minimizar las opiniones negativas y a potenciar la creación de positivas.

En el mismo sentido también hay que hacer referencia al artículo de Inversini et al. (2010). Esta investigación utiliza la imagen y la reputación online como una métrica para dar sentido a la enorme cantidad de contenidos generados por los usuarios disponibles en línea. Los contenidos generados por los consumidores que permiten una comunicación bidireccional para compartir opiniones en los medios sociales están cobrando especial relevancia en el sector turístico al ser empresas de servicios. Debido a las características de los servicios (intangibles, inseparables, perecederos y heterogéneos) la imagen y la reputación online se consideran cruciales. Así, es posible argumentar la construcción de reputación online en las redes sociales, y puede ser administrado por las organizaciones de manera integral para atraer a más turistas.

Según Lim (2010), los medios sociales ofrecen tecnologías que pueden facilitar la funcionalidad online y monitorear datos recopilados, que se pueden utilizar para desarrollar servicios para satisfacción del cliente. En este sentido, en los trabajos de Litvin et al. (2008) y Liu y Park (2015) especifican una serie de estrategias para aprovechar el poder de los medios sociales en el sector turístico y estimular sus esfuerzos de marketing. Establecen que el marketing en el sector turístico debe tener en cuenta que cada vez exista más clientes en la red que se ven influenciados por las opiniones de otros clientes, por lo tanto, deben aprender a controlar y no ser controlados por esta nueva fuerza. Además, consideran los medios sociales como una fuente importante de información que puede ser utilizada para el desarrollo de una serie de estrategias de negocio en el sector turístico, incluyendo la mejora de la satisfacción del cliente a través de la mejora del servicio, la resolución de problemas, el conocimiento de la experiencia de los visitantes, así como la imagen y la reputación del producto turístico.

Una de las principales funciones de estos medios sociales es establecer un canal interactivo de comunicación, que sea mutuamente beneficioso para las partes involucradas, de esta manera, ofrece un medio para que los turistas expresen sus deseos, y brinda a los proveedores de servicios turísticos una herramienta para obtener comentarios de los clientes (Leung et al. al., 2013; Oz, 2015). Además, estas plataformas han sido reconocidas como redes de intercambio de conocimiento porque les permiten a los consumidores del turismo conectarse, compartir e interactuar con otros $(\mathrm{Oz}, 2015)$.

Por esta razón, los medios sociales, como plataformas interactivas, están llamando la atención de la industria del turismo. Además, la gran adopción y el uso extensivo de los medios sociales han tenido un impacto influyente en las funciones de marketing y gestión estratégica y operativa en el campo del turismo (Law et al., 2014).

\subsection{Medición del ROI en las redes sociales.}

Los medios sociales son diferentes a los medios tradicionales, por lo tanto, se requiere un enfoque diferente para su medición. La medición del valor de un negocio desde la tecnología de la información ha sido tradicionalmente problemática, lo que se extiende a los medios sociales (Stockdale et al., 2012; Geho et al., 2011). Si bien el impacto de la actividad online se puede medir utilizando métricas cuantitativas definidas, las redes sociales generan una cantidad considerable de datos cualitativos que las métricas tradicionales por sí solas no pueden abordar o cuantificar en términos monetarios (Fisher, 2009). Por lo tanto, no hay una sola manera de medir el impacto de las redes sociales y así calcular el ROI. 
Aunque se puede argumentar que sólo las ganancias financieras pueden ser medidas en valor monetario, las ganancias no financieras de los medios sociales pueden ser igualmente beneficiosas ya que otorgan unos premios tales como una mejor comunicación con los clientes, la conciencia de marca, etc. Sin embargo, aunque estas consideraciones pueden ser ventajosas para cualquier negocio, medir tales beneficios intangibles es problemático. Mientras, algunas métricas, como "el aumento de los seguidores de Facebook" o "el aumento de seguidores en Twitter", no se refieren necesariamente a un aumento de las ventas, es claro ver que la presencia de una empresa a través de las plataformas de medios sociales, en última instancia, puede conducir a la ganancia financiera (Blanchard, 2012).

Según Powell et al. (2011), en el pasado la comercialización era un proceso difícilmente calculable. Las empresas invertían en comunicaciones de marketing con poca o ninguna certeza del resultado exitoso de una campaña o esfuerzo de marca. Esto ha cambiado significativamente y, con la aparición de las redes sociales, los vendedores pueden ahora aplicar muchas de las lecciones aprendidas de la medición de los medios tradicionales a la medición de las redes sociales. Ahora los vendedores deben pasar a medir la efectividad de sus inversiones en marketing de medios sociales.

El ROI simplemente se refiere a la idea de que algo de valor ha resultado de una inversión de tiempo, energía o dinero. En los círculos financieros, el ROI suele reducirse a una fórmula (Bragg, 2012), se calcula simplemente restando el costo de una inversión de los ingresos recibidos de la inversión, dividido por el mismo costo de inversión. Es normal que las empresas busquen ganancias, pero los medios sociales no pueden interpretarse únicamente como una medida de tales beneficios y por esta razón es importante estar familiarizado con otras formas de utilización del ROI. En primer lugar, si una institución está presente en los medios sociales, es porque ya hay alguien hablando sobre ello y, en segundo lugar, estos medios no ofrecen nada más que nuevas maneras de interactuar y comunicarse. Evitarlos es como negarse a tener un teléfono o una sala de reuniones. Además, la necesidad de comparar el social media marketing con la publicidad más tradicional nos hace perder de vista el aspecto más importante de la comunicación 2.0, que es su bidireccionalidad (Schmidt, 2014).

En el marketing offline, el ROI se calcula en base a ciclos completos de promoción y marketing. Si se hacen campañas en varios medios y formatos (televisión, radio, prensa, etc..) el ROI se calcula en base a la inversión y el aumento de las ventas (ROI = [(ingresos - inversión) / inversión $\left.]^{*} 100\right)$. Con la llegada de internet, el marketing online, el comercio electrónico y la facilidad de monitorizar las ventas en tiempo real (realizadas en internet) el ROI empezó a ser calculado para cada acción y cada formato, por ejemplo, el impacto que tiene un banner en una campaña de publicidad en una página web. Con los medios sociales se abre un nuevo entorno social donde no se dan acciones comerciales directas, sino que aparecen nuevas reglas y dinámicas basadas en conversaciones y relaciones. Los usuarios ahora pasan más tiempo en los medios sociales que usando los buscadores o leyendo noticias en publicaciones online. En este nuevo entorno social las marcas poco a poco se atreven a entrar y participar de las conversaciones y relacionarse con los usuarios (Sobejano y Cavalcanti, 2011).

En el estudio de Lloret (2011) el ROI se define como un mero indicador de la rentabilidad de la inversión, en el que se consideran los costes directos y los ingresos de cada transacción. El marketing en los medios sociales está lleno de intangibles y su medición se convierte en una de las mayores necesidades actuales para las empresas. El ROI invita a traducir toda la comunicación en medios sociales en dinero. Sin embargo, mientras que los costes son bastante claros, la ganancia derivada de cada actividad es más difícil de alcanzar. Muchos tienden a simplificar el retorno reduciéndolo únicamente sobre la base de las ventas directas realizadas a partir de los enlaces publicados en las redes sociales. Mientras que este retorno es interesante para una empresa cuya actividad está vinculada al comercio electrónico, es completamente inadecuada para cualquier otra institución, y especialmente para una empresa que no tienen tiendas online.

Cosenza (2012) especifica que el uso eficaz de los medios sociales en los negocios no es sencillo, por lo tanto, determinar el valor tampoco es un proceso fácil. La capacidad de vincular la actividad con los valores del negocio es fundamental, si se quiere dedicar tiempo, recursos y presupuesto a las redes sociales, las inversiones deben estar justificadas. De hecho, las estrategias de los medios de comunicación social deben demostrar el valor a largo plazo y la contribución al éxito empresarial.

Mientras que muchas empresas ya están invirtiendo en medios sociales, la realidad es que la mayoría lo hacen sin la capacidad de demostrar ningún ROI. A pesar de que intervenir en los medios sociales es barato o gratuito, el tiempo y los recursos todavía tienen costes fijos. Por ello, si se aumenta la presencia o se aplican mayores recursos, la inversión sube exponencialmente. El éxito es definible y alcanzable, este requiere una definición basada en las intenciones, los objetivos y el valor mutuo en 
toda la organización. No es posible medir el ROI para algo si no se ha establecido primero que se va a medir (Cosenza, 2012).

Según Martínez (2010) los medios sociales pueden ofrecer visitas, conversión, fidelización y feedback. A través de varios estudios se ha medido en términos económicos la relación del usuario con la marca en las diferentes plataformas de medios sociales. En general, los estudios han revelado que los usuarios gastaban significantemente más dinero en los productos de los que son fans, en comparación con los consumidores que no lo son. La compra de productos no es el único factor beneficioso detectado para las marcas que invierten en Facebook o Twitter, ya que se ha detectado que también hay un aumento de la lealtad y la afinidad. Por lo tanto, a la cuestión de "cuánto vale un fan" puede decirse que el valor de cada seguidor no es algo exacto, sino que depende de la gestión que la marca realice de la comunicación. La medición de la audiencia online en los social media continúa siendo un desafío para el sector publicitario, tanto académico como profesional. Tanto los anunciantes como las agencias deben de ser conscientes del cambio que se está produciendo en la toma de contacto con el usuario en la red, el concepto de audiencia deberá ir adaptándose mediante la incorporación de nuevas métricas y dimensiones acordes a la realidad del medio.

Una vez que las empresas han incorporado el manejo de las redes sociales en sus estrategias de negocio, es natural esperar que los departamentos de marketing y comunicación desarrollaran instrumentos de medición de la eficacia de dichas estrategias. Existe un debate abierto sobre cómo obtener datos objetivos para calcular el impacto asociado al uso de este tipo de herramientas (Murgui, 2011).

No existen normas que definan de forma clara y fácil cómo se obtienen los datos, cuáles son las métricas más adecuadas para obtener la información (Leeflang 2014). Cuando se aborda la medición de la rentabilidad en medios sociales se contempla un beneficio en valor, el llamado IOR (Impact On Relationship) o Retorno en Relaciones. El IOR se considera como el valor acumulado que otorga una persona a una marca, debido al cultivo de esta relación. El IOR es un valor y se puede medir su impacto a través de recomendaciones, participación o lealtad. Los medios sociales son fácilmente rentables para conseguir beneficios no económicos, de ahí que se hable también del SROI o ROI Social (Taladriz-Mas, 2013).

Una vez que el foco de retorno de la inversión con respecto a los medios sociales se ha ampliado, las empresas pueden empezar a considerar el "impacto de las relaciones" o IOR. Este enfoque se centra en el análisis de las interacciones de medios sociales entre una empresa y sus fans / seguidores (Geho y Dangelo, 2012).

Para medir este ROI a través de las redes sociales se necesita la creación de un conjunto de indicadores y métricas únicas, que mida el impacto en los usuarios en la web social y sirva también como análisis competitivo (González Fernández-Villavicencio, 2016).

Los indicadores clave de desempeño son métricas utilizadas para cuantificar objetivos que reflejan el rendimiento de una organización. El acto de monitorizar los indicadores clave de desempeño en tiempo real se conoce como monitorización de actividad de negocio. Castelló Martinez (2012) comenta que un KPI (Key Performance Indicator) es un indicador clave de rendimiento, una variable que está ligada a un objetivo en los medios sociales y permite monitorizar el estado de avance o grado de cumplimiento del objetivo. Los KPIs sirven para saber cómo dinamizar los canales de la empresa en redes sociales ya que los resultados darán pistas sobre cómo seguir aplicando la estrategia.

Por lo tanto, ante la diversidad y la complejidad que requiere el cálculo del ROI en las redes sociales, en este estudio se va a tomar en consideración la utilización de una serie de indicadores derivados del modelo PRGS que va a medir la presencia y la actividad de los destinos turísticos en las redes sociales.

\section{Metodología}

Para estudiar el ROI en este estudio se ha llevado a cabo un análisis y monitorización de la actividad de las redes sociales oficiales que utilizan las delegaciones provinciales de turismo de las 8 provincias andaluzas para promocionarse como destino turístico.

Para llevar a cabo el análisis se ha tomado como base el modelo PRGS, propuesto por IAB Spain Research para elaborar su estudio de la "actividad de las marcas en medios sociales" de los años 2012-2016. Este modelo ha sido utilizado en diversos estudios como, por ejemplo, los realizados por Castelló (2013), Sánchez y Giraldo (2015) y Giraldo y María Dolores (2017).

Este modelo se fundamenta en 4 variables (Presencia, Respuesta, Generación y Sugerencia) para medir la presencia y la actividad de las marcas en redes sociales (Giraldo y Sánchez, 2014): 
- P (Presencia): viene dada por el número de fans o seguidores y el número de publicaciones que la marca realiza en la página. $\mathrm{P}=\mathrm{n}^{\circ}$ de seguidores y $\mathrm{P}=\mathrm{n}^{0}$ de post.

- $\mathrm{R}$ (Respuesta): viene dada por el número de me gusta de los usuarios que los mismos generan ante las publicaciones de la marca. $\mathrm{R}=$ likes o me gusta $/ \mathrm{n}^{\circ}$ de fans.

- G (Generación): viene dada por el número de comentarios de los usuarios que los mismos generan ante las publicaciones de la marca. $\mathrm{G}=$ comentarios $/ \mathrm{n}^{\circ}$ de fans.

- S (Sugerencia) viene dada por el número de comparticiones o recomendaciones de los usuarios que los mismos generan ante las publicaciones de la marca. $\mathrm{S}=$ Compartir $/ \mathrm{n}^{\circ}$ de fans.

Las variables de "respuesta", "generación" y "sugerencia" se han unido en una sola variable denominada "engagement $\mathrm{o}$ actividad", que corresponde a la suma de las tres anteriores. La formulación y el cálculo del "engagement" ha sido tratada en varios estudios como los de Castelló (2012), Oviedo-García et al. (2014) y Buhalis y Mamalakis (2015).

Además, como aportación original al modelo, se ha considerado de interés para analizar la actividad añadir la variable "tipo de publicaciones", a través de la cual se obtiene información acerca del tipo de publicaciones de las redes sociales de los destinos.

De esta manera, se toma en consideración las variables "engagement" y "tipo de publicaciones" para cumplir el segundo objetivo específico.

De esta manera, las variables y los indicadores de rendimiento (KPIs) usados en el análisis han sido los siguientes (tabla 1):

\section{Tabla 1: Variables e indicadores de rendimiento utilizados en el análisis junto con su descripción}

\begin{tabular}{|c|c|l|}
\hline Variable & \multicolumn{1}{|c|}{ Indicadores } & \multicolumn{1}{c|}{ Descripción } \\
\hline \multirow{2}{*}{ Presencia } & Número de seguidores & $\begin{array}{l}\text { Establece el número de seguidores } \\
\text { de la red social del destino }\end{array}$ \\
\cline { 2 - 3 } Engagement o actividad & $\begin{array}{c}\text { Número de publicaciones y } \\
\text { publicaciones/día }\end{array}$ & $\begin{array}{l}\text { Índica cuantas publicaciones ha } \\
\text { realizado el destino }\end{array}$ \\
\hline número de publicaciones & $\begin{array}{l}\text { Índica cuál es el número total de } \\
\text { las interacciones de los usuarios por } \\
\text { publicación de la página mediante } \\
\text { la suma de las reacciones (me gusta, } \\
\text { me encanta, sorprendido, risa, etc.), } \\
\text { los comentarios y las veces que se } \\
\text { ha compartido entre el número de } \\
\text { publicaciones }\end{array}$ \\
\hline Publicaciones & Tipo de publicaciones & $\begin{array}{l}\text { Indica que tipo de publicaciones se } \\
\text { ha realizado, bien en enlaces, videos } \\
\text { o imágenes }\end{array}$ \\
\hline
\end{tabular}

Fuente: Elaboración propia.

Para la medición de los indicadores de las páginas de redes sociales de las 8 provincias de Andalucía se ha empleado la herramienta online Fanpage Karma que permite el análisis y la monitorización de medios sociales entre las que destacan Facebook, Twitter, YouTube e Instagram. La herramienta online Fanpage Karma ha sido utilizada en varios estudios de investigación para el análisis de redes sociales entre los que destacan los de Jayasingh, S. y Venkatesh, R. (2015), Huertas, A. y Marine-Roig, E. (2016), Martínez-Fernández et al. (2015) y Márquez-Domínguez et al. (2017). Además, también ha sido utilizado para la realización de estudios turísticos como los de Wozniak et al. (2017), Amboage (2015) y Huertas et al. (2015).

En este caso se han seleccionado como objeto de análisis las redes sociales oficiales de las delegaciones de turismo de las 8 provincias andaluzas por considerarse las más relevantes para para estudiar el turismo de la zona. De esta manera, se ha obtenido una base de datos con las redes sociales oficiales de 
turismo que utilizan las 8 provincias de Andalucía con su enlace correspondiente. Se han tenido en cuenta las redes sociales de Facebook, Twitter, Instagram y Youtube por considerarse las más destacadas en el sector turístico (Beezhotels, 2016). La obtención de los datos se realizó para un periodo de tiempo de 6 meses, desde el día 1 de mayo de 2017 hasta el 1 de noviembre de 2017, ya que se considera un periodo de tiempo suficiente para la obtención de datos significativos sobre la intervención de las provincias andaluzas en sus redes sociales oficiales.

\section{Resultados}

A continuación, se especifica los resultados obtenidos en el análisis de las redes sociales de las 8 provincias andaluzas en el periodo de 6 meses teniendo en cuenta las variables ya comentadas de presencia, engagement y tipo de publicaciones.

\subsection{Presencia}

El estudio para comprobar la presencia de las provincias andaluzas en las redes sociales oficiales para su promoción turística se ha dividido en dos apartados teniendo en cuenta los siguientes indicadores: primero se analiza el número de seguidores en cada red social y, posteriormente, el número de publicaciones realizadas en cada red social. Para ello se tiene en cuenta las redes sociales de Facebook, Twitter, Instagram y Youtube.

Antes de comenzar el análisis cabe destacar que tanto en Facebook, Twitter y Youtube las 8 provincias andaluzas tienen un perfil oficial creado para su promoción turística. En Instagram son 6 las provincias que constan de perfil oficial, siendo las provincias de Córdoba y Jaén las que no intervienen en esta red social. También destacar que la provincia de Málaga, aunque tiene un perfil creado en las redes sociales especificadas anteriormente solamente ha creado contenido en Youtube durante el periodo de estudio.

En los resultados respecto al número de seguidores puede comprobarse como destaca con diferencia Facebook con el 53,1\% del total. Le sigue Twitter con el 33,3\%, en tercer lugar, está Instagram con el 11,1\% y en último lugar Youtube con el 2,5\% (gráfico 1).

\section{Gráfico 1: Media de número de seguidores por red social}

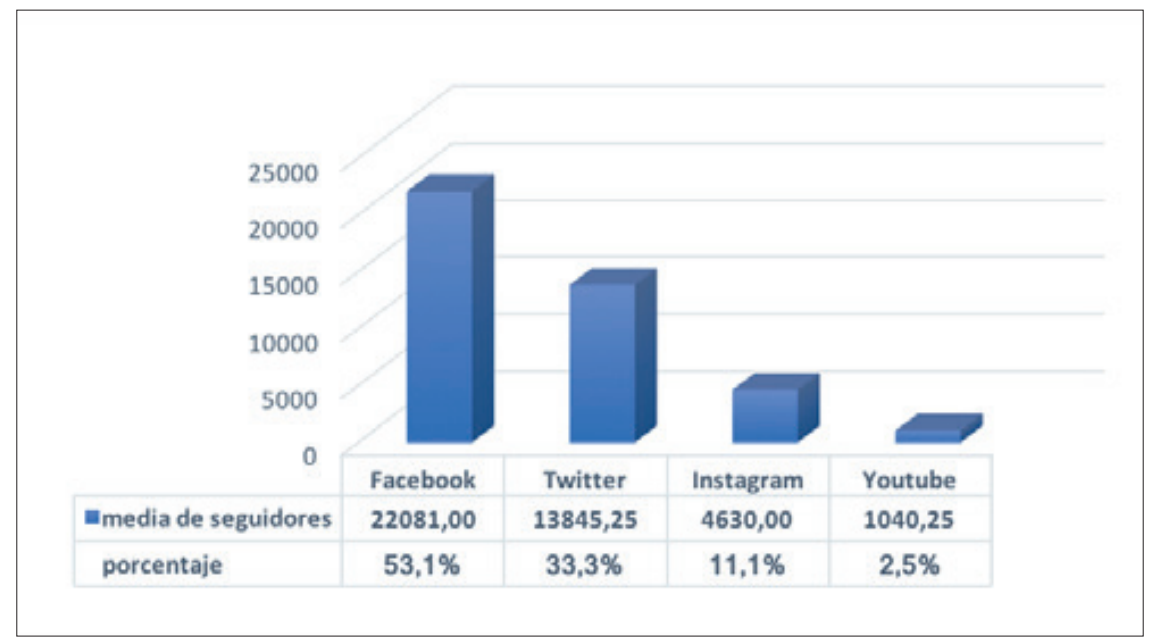

Fuente: Elaboración propia.

En lo que respecta al número de publicaciones Facebook sigue siendo la red social en la que de media se realizan más publicaciones con un $47,5 \%$, Twitter está en segundo lugar con un $31 \%$ y se aprecia un aumento del porcentaje total de Instagram y Youtube respecto al número de seguidores con un 16,2\% y un $5,3 \%$ respectivamente (gráfico 2 ). 


\section{Grafico 2: Media de número de publicaciones por red social}

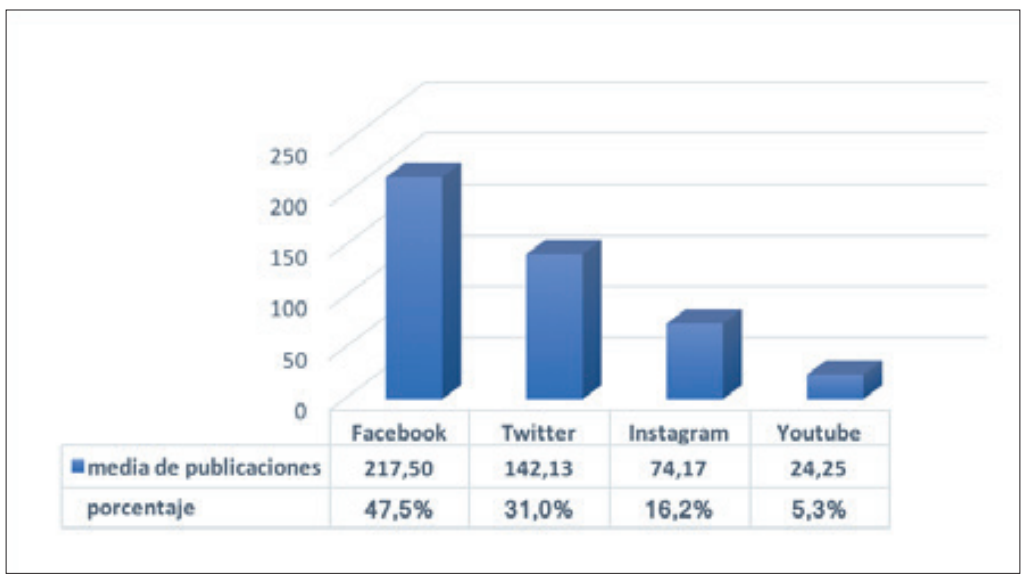

Fuente: Elaboración propia.

\subsection{Engagement}

Una vez se ha comprobado la presencia de las provincias de Andalucía como destino turístico en las redes sociales resulta de especial interés analizar cuál es la efectividad de su utilización medida a través de la variable engagement.

Existen varias fórmulas para calcular el engagement de un determinado perfil de red social, en este caso se ha teniendo en cuenta el número de publicaciones.

Engagement: $\mathrm{n}^{\circ}$ total de interacciones ( $\mathrm{n}^{\mathrm{o}}$ de reacciones $+\mathrm{n}^{\circ}$ de comentarios $+\mathrm{n}^{0}$ de veces compartido) $/ \mathrm{n}^{\mathrm{o}}$ de publicaciones

A continuación, mediante esta fórmula, se ha calculado el engagement de cada perfil de redes sociales de las provincias andaluzas.

En el gráfico 3 puede verificarse que las dos redes sociales con mayor engagement con mucha diferencia respecto a las demás son Instagram y Facebook respectivamente. Se puede considerar, por tanto, que los usuarios participan e interaccionan mucho más con estas dos redes sociales. Llama la atención el caso de Instagram que pese a no tener un gran número de seguidores ni publicaciones sea la red social donde se genera mayor engagement en este caso.

\section{Grafico 3: Media de engagement por red social}

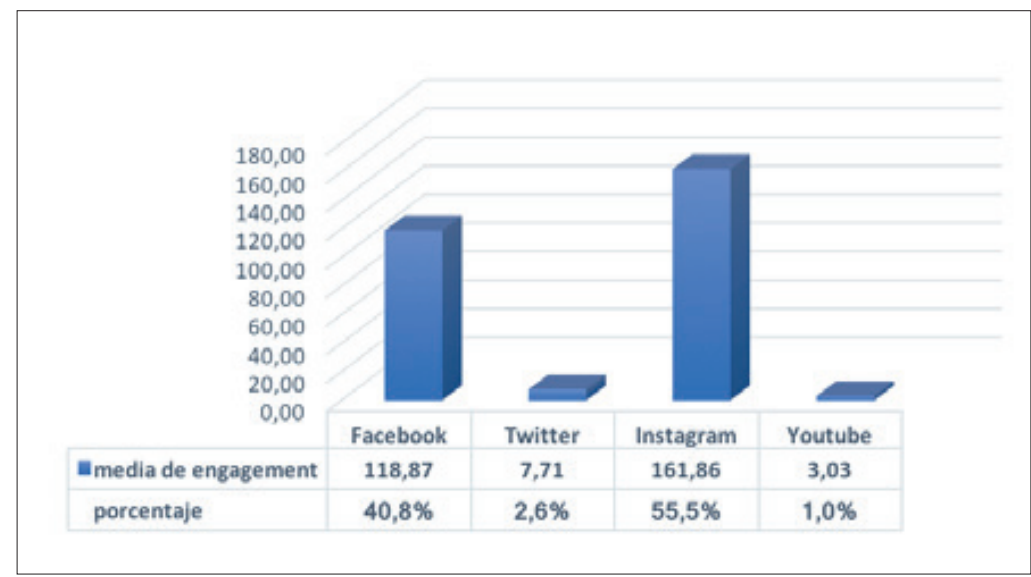

Fuente: Elaboración propia. 


\subsection{Tipo de publicaciones}

En este apartado se ha analizado el tipo de publicaciones realizadas por los diferentes perfiles de redes sociales de las provincias andaluzas. Se verifica, por tanto, la media de tipo de publicaciones por red social llevadas a cabo durante los 6 meses objeto de estudio.

En el gráfico 4 se comprueba la media de las publicaciones en Facebook por cada tipo. Destaca con gran mayoría los mensajes o post de imágenes, siendo el 70,7\% del total, mostrando los destinos turísticos una apuesta manifiesta por realizar publicaciones de carácter visual. Le sigue, a bastante distancia, los mensajes sobre videos con el $26,2 \%$ y, por último, con un margen muy escaso, los mensajes de enlace con el 3,1\%.

\section{Grafico 4: Media de tipos de publicaciones en Facebook}

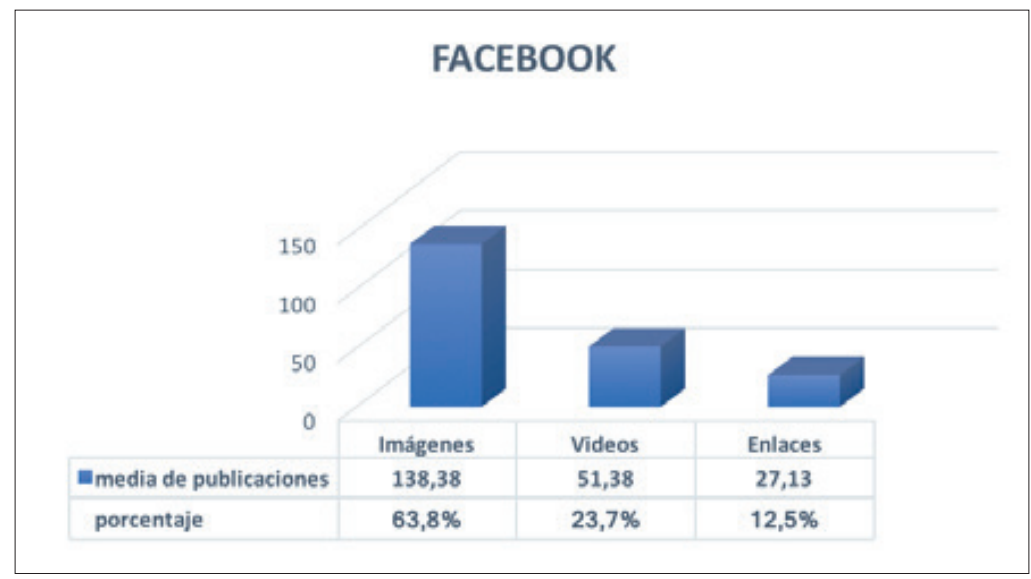

Fuente: Elaboración propia.

En lo que respecta a Twitter (gráfico 5), se contrasta que la mayoría de los mensajes o tuits a lo largo de los 6 meses van referidos a imágenes con un $37,8 \%$, seguido de solo texto con el $27,1 \%$, posteriormente estarían los mensajes de enlaces e imágenes con el $23 \%$ y, por último, los mensajes que solo contienen enlaces con el 12,1\%. Puede comprobarse en el caso de Twitter que el contenido está más repartido que en Facebook, destacando la importancia de las imágenes pese a no ser una red social propicia para ello.

\section{Grafico 5: Media de tipos de publicaciones en Twitter}

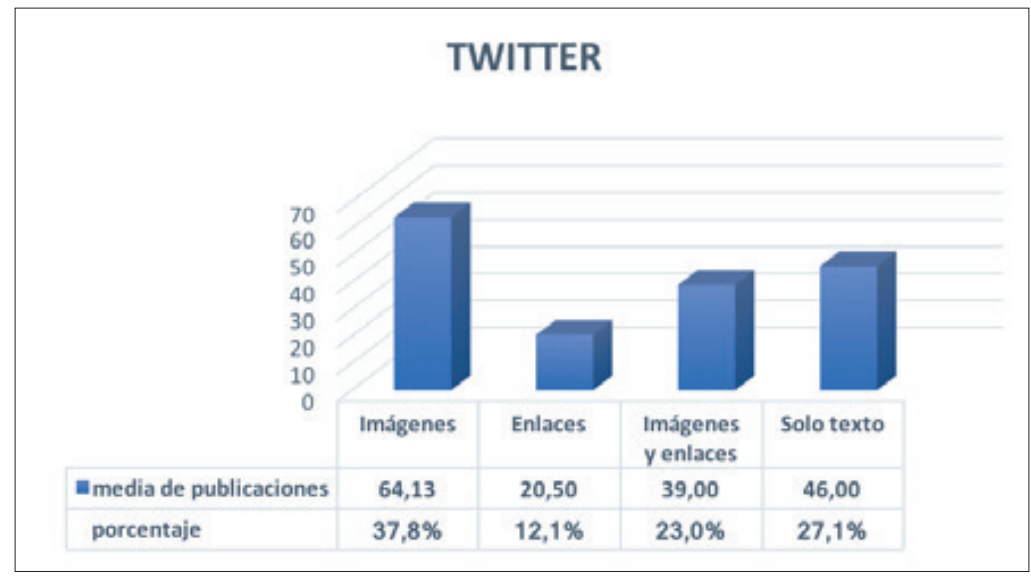

Fuente: Elaboración propia. 
La red social de Instagram solo permite la publicación de contenido mediante imágenes y videos. En este caso puede comprobarse en el grafico 6 que el 78,6\% de las publicaciones son imágenes mientras que el $21,4 \%$ son videos.

\section{Grafico 6: Media de tipos de publicaciones en Instagram}

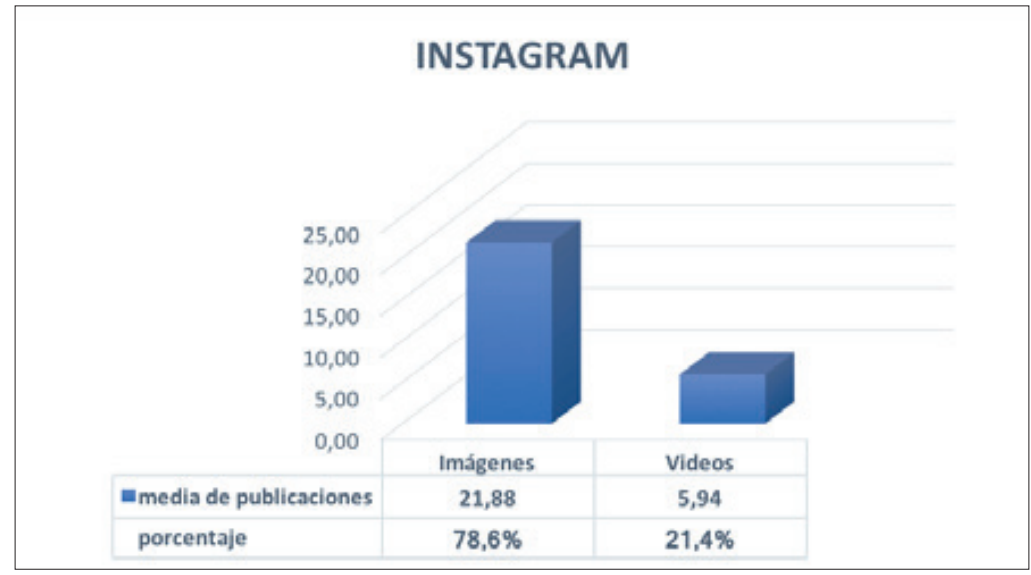

Fuente: Elaboración propia.

Además, en Facebook se conocen las interacciones obtenidas por cada tipo de publicación (gráfico 7). Puede comprobarse que las publicaciones con mayor interacción son los videos con más de un $50 \%$ del total, seguida de las imágenes con un $36 \%$ y con las que menos interaccionan los usuarios son con las de enlaces con un $9,4 \%$.

\section{Gráfico 7: Media de interacción de las publicaciones en Facebook}

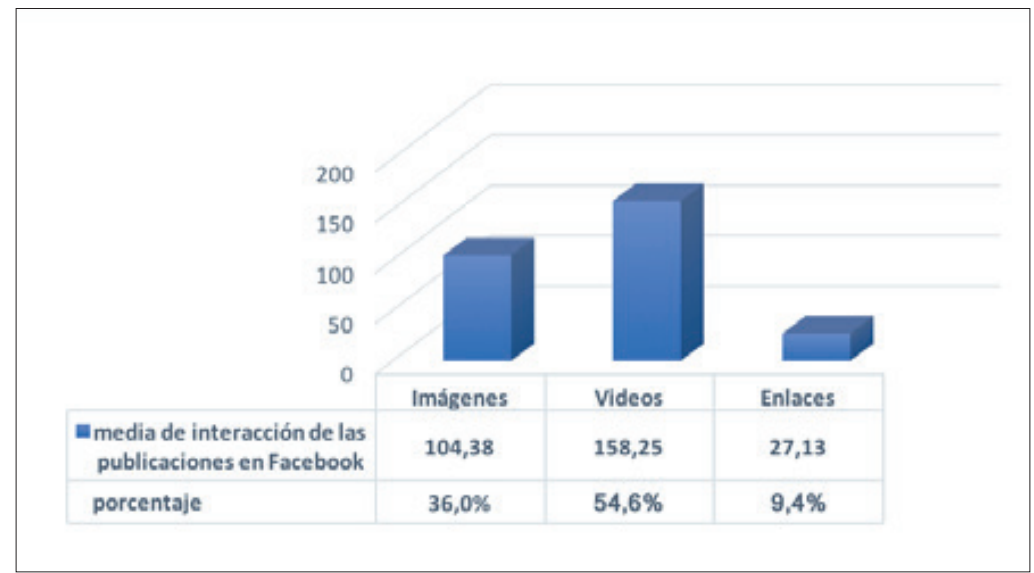

Fuente: Elaboración propia.

\subsection{Resultados respecto a las provincias andaluzas}

En este apartado se comentan los resultados principales referidos a las provincias andaluzas. Los resultados se especifican para cada una de las redes sociales. 


\section{- Facebook}

En Facebook en general se observa una muy buena presencia oscilando entre el máximo de los 59509 seguidores de Cádiz y el mínimo de los 5900 seguidores de Jaén. Destacan principalmente tres de ellas: Cádiz, Almería y Huelva. Cádiz tiene casi 60000 seguidores, seguido de los más de 44000 de Almería y los más de 30000 de Huelva (gráfico 8).

\section{Gráfico 8: Número de seguidores en Facebook por cada provincia andaluza}

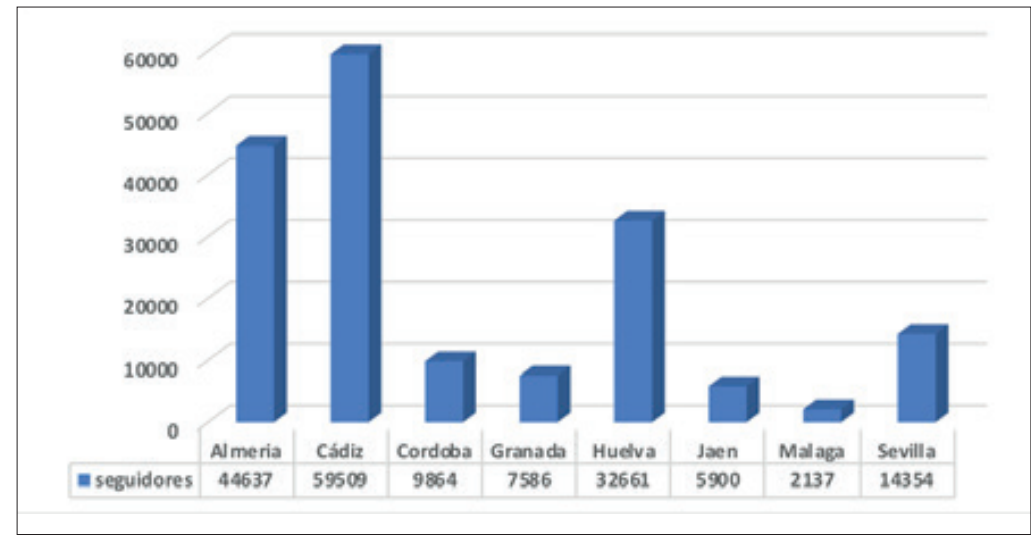

Fuente: Elaboración propia.

En el número de publicaciones oscila entre las 483 de Almería y las 61 de Granada. Siguen destacando de nuevo Almería y Cádiz, con 483 y 365 publicaciones respectivamente. Posteriormente, a más distancia, están Sevilla, Jaén y Huelva con 297, 218 y 210 publicaciones respectivamente (gráfico 9).

\section{Gráfico 9: Número de publicaciones en Facebook por cada provincia andaluza}

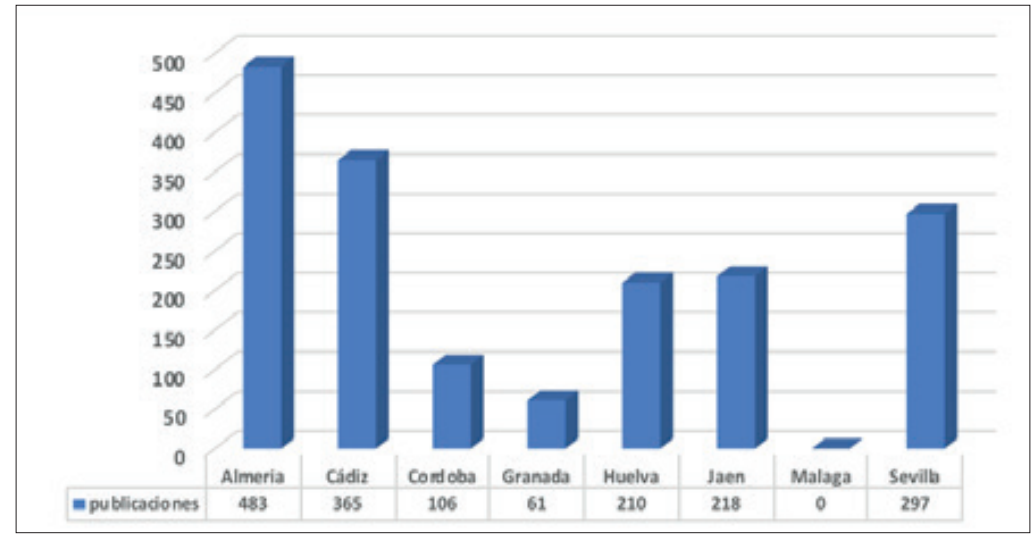

Fuente: Elaboración propia.

Por último, es interesante conocer la interacción en Facebook ya que como se ha comprobado anteriormente es, junto con Instagram, la red social que genera mayor engagement. En este caso, comprobamos que el nivel de engagement oscila entre los 379 de Cádiz y los 10,26 de Jaén. Destacan muy por encima de las demás las provincias de Cádiz, Almería y Huelva cuyas interacciones por publicación se sitúan en 379,252 y 220 respectivamente (gráfico 10). 


\section{Gráfico 10: Número de interacciones por publicación en Facebook por cada provincia andaluza}

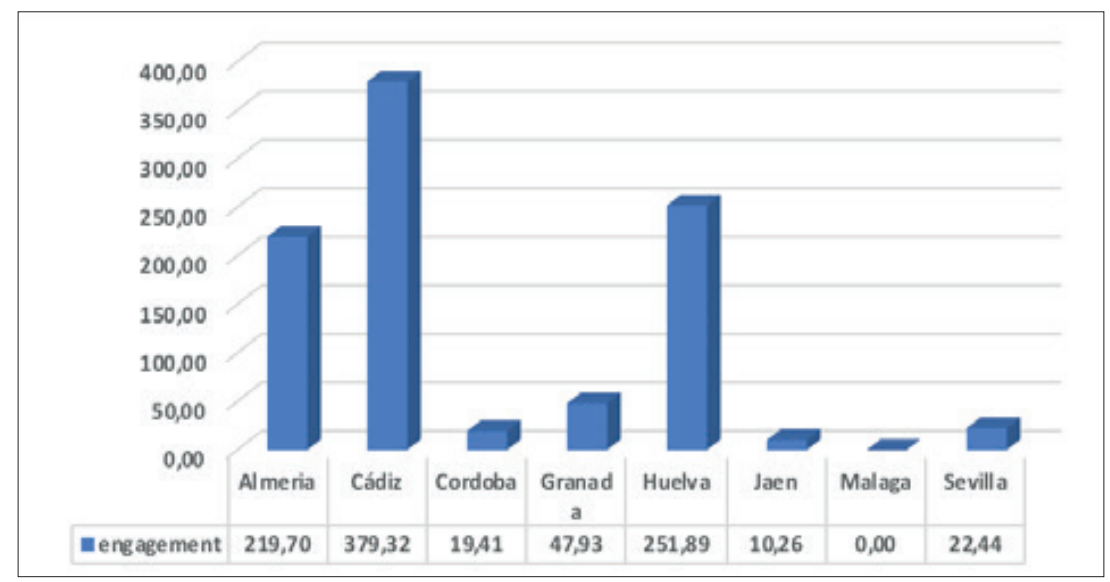

Fuente: Elaboración propia.

\section{- Twitter}

En Twitter se aprecia en general una buena presencia y participación. En el número de seguidores oscila entre el máximo de Cádiz con casi 30000 seguidores y el mínimo de Córdoba con 6000. La provincia de Cádiz destaca con diferencia respecto a las demás, situándose posteriormente Granada y Almería con 20000 y 15000 seguidores respectivamente (gráfico 11).

\section{Gráfico 11: Número de seguidores en Twitter por cada provincia andaluza}

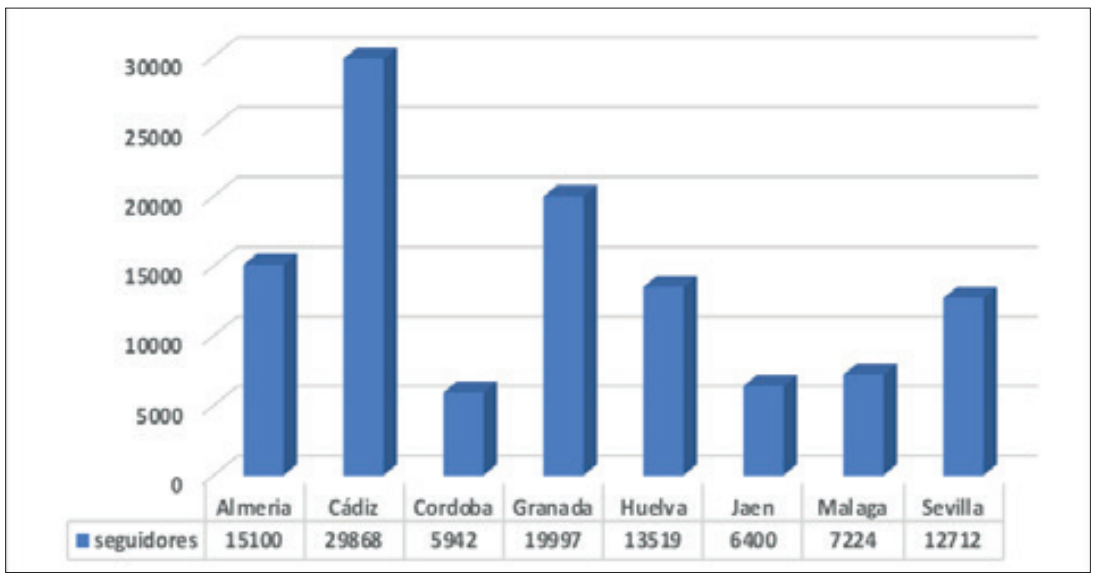

Fuente: Elaboración propia.

Respecto al número de publicaciones hay tres provincias que destacan con diferencia respecto a las demás, situándose Cádiz con 315, Huelva con 276 y Jaén con 268, una cantidad bastante elevada. Lo que hace reducir la media de publicaciones en esta red social es que en las provincias de Málaga y Córdoba no se ha realizado ninguna publicación en la fecha de estudio (gráfico 12). 


\section{Gráfico 12. Número de publicaciones en Twitter por cada provincia andaluza}

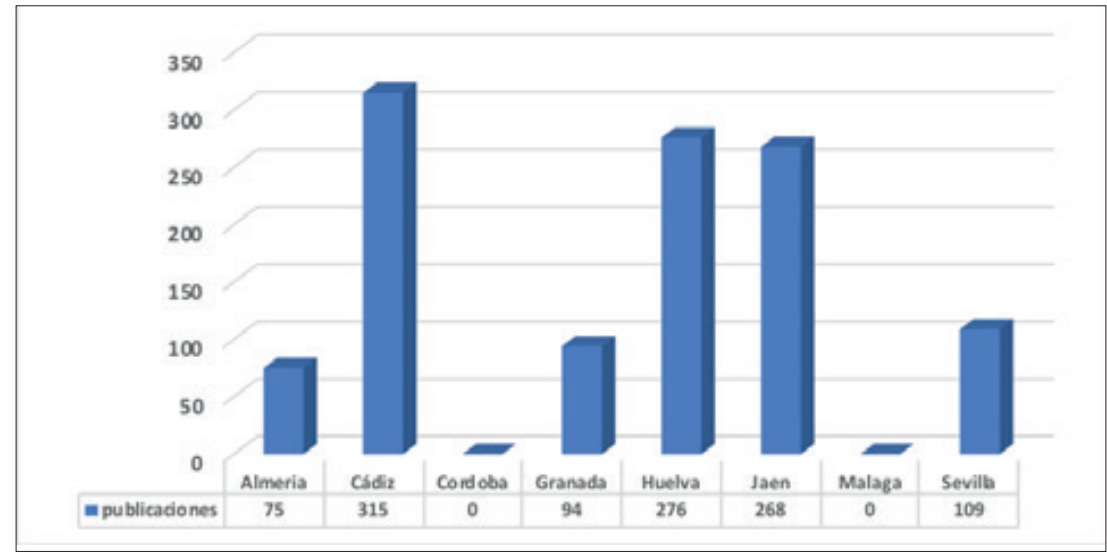

Fuente: Elaboración propia.

Aunque el nivel de engagement en Twitter no es alta a continuación se especifican las provincias con más interacciones por cada publicación. De nuevo destacan tres provincias, en esta ocasión las de Almería, Cádiz y Huelva con 16,75, 14,84 y 14 interacciones por publicación, a bastante distancia se encuentran Sevilla y Granada con poco más de 7 interacciones por publicación. Jaén solo cuenta con una interacción por publicación y Córdoba y Jaén con ninguna, lo que hacer bajar la media de interacciones para esta red social (gráfico 13).

\section{Gráfico 13: Número de interacciones por publicación en Twitter por cada provincia andaluza}

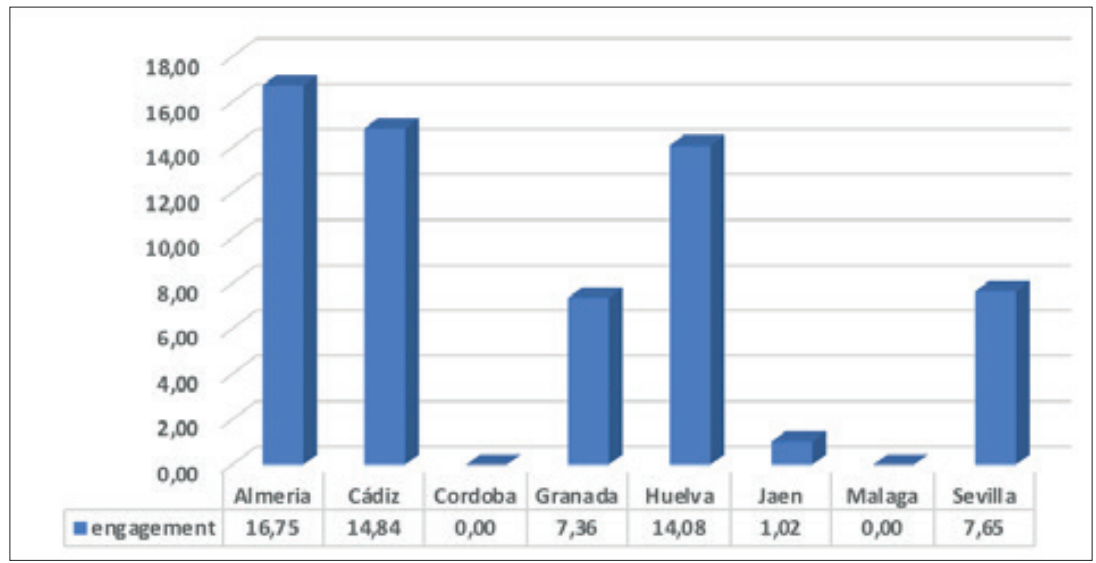

Fuente: Elaboración propia.

\section{- Youtube}

Como se ha comprobado anteriormente, la red social de Youtube los resultados de presencia y actividad son bastante inferiores que en las demás redes sociales. Aún así, es de interés conocer que provincias intervienen más en esta red social. Respecto a los números de seguidores hay bastante disparidad entre provincias. Destaca sobre las demás Almería con casi 3000 seguidores, seguido de Cádiz con 1858. Ya a bastante diferencia se encuentran las redes sociales de Jaén y Málaga con 1271 y 920 respectivamente (gráfico 14). 


\section{Gráfico 14: Número de seguidores en Youtube por cada provincia andaluza}

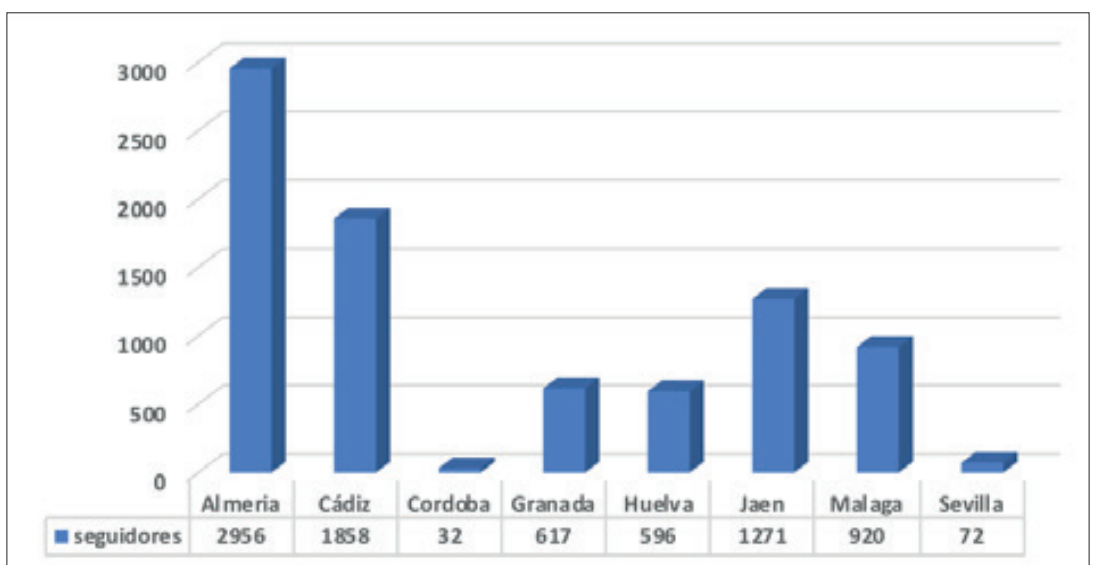

Fuente: Elaboración propia.

Hay provincias que han intervenido activamente en esta red social publicando más de 39 videos en el periodo de estudio como son Jaén, Málaga y Cádiz con 91, 44 y 39 respectivamente. De las demás 4 de ellas sí han subido videos, aunque con menos frecuencia (entre 1 y 6) y solo la provincia de Córdoba, pese a tener un perfil en esta red social, no ha subido ningún video en el periodo de estudio (gráfico 15).

\section{Gráfico 15: Número de publicaciones en Youtube por cada provincia andaluza}

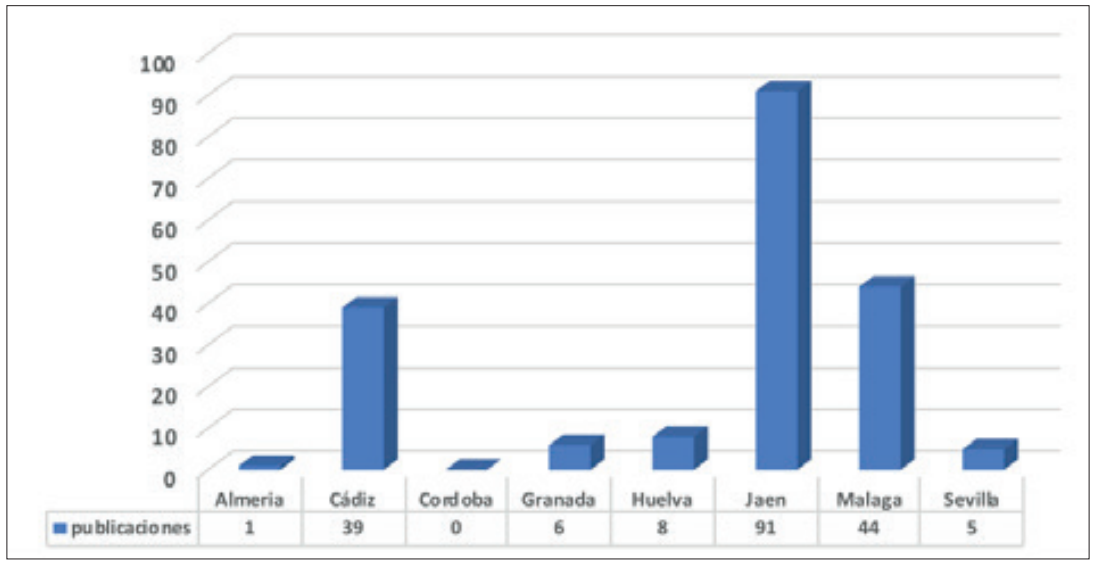

Fuente: Elaboración propia.

Respecto al engagement de nuevo destacan las tres provincias anteriores que son las que intervienen activamente en esta red social, así Jaén, Cádiz y Málaga han tenido 197, 119 y 49 interacciones por publicación respectivamente. Las demás provincias no superan las 23 interacciones por publicación (gráfico 16). 


\section{Gráfico 16: Número de interacciones por publicación en Youtube por cada provincia andaluza}

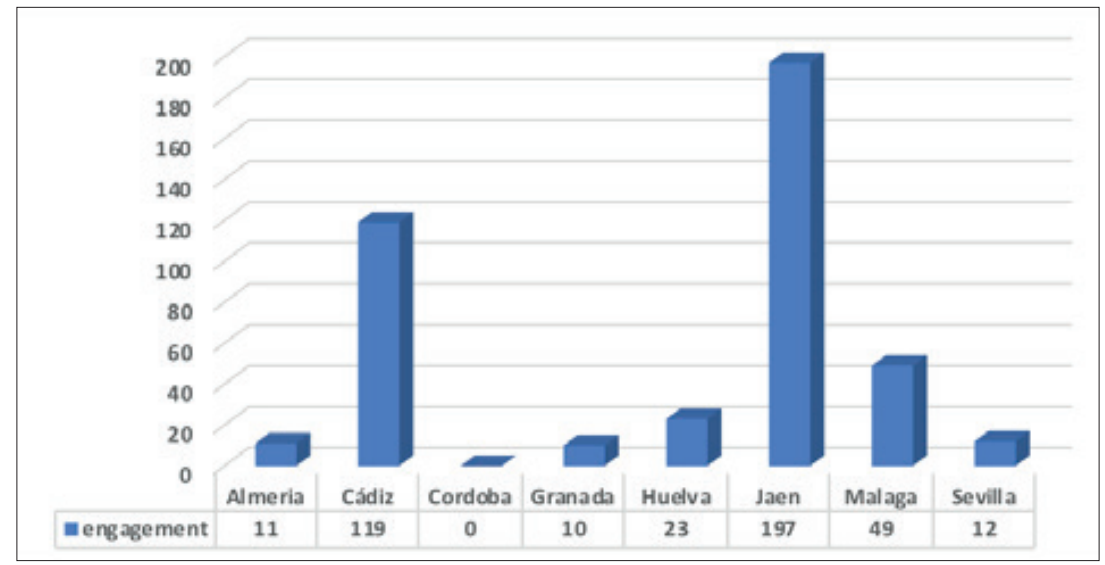

Fuente: Elaboración propia.

\section{- Instagram}

En lo que respecta a Instagram, como se ha comprobado anteriormente, los números de seguidores y publicaciones son inferiores a Facebook y Twitter, no obstante, destaca sobre todo los grandes resultados alcanzados en el engagement situándose incluso por delante de Facebook.

En el número de seguidores oscila entre el máximo de Cádiz con más de 15000 y el mínimo de Málaga con 785. La provincia destaca con bastante diferencia respecto a las demás, posteriormente destaca Huelva con más de 6000 seguidores y Almería con más de 3600. Las provincias de Granada, Sevilla y Málaga están por debajo de los 1430 seguidores (gráfico 17).

\section{Gráfico 17: Número de seguidores en Instagram por cada provincia andaluza}

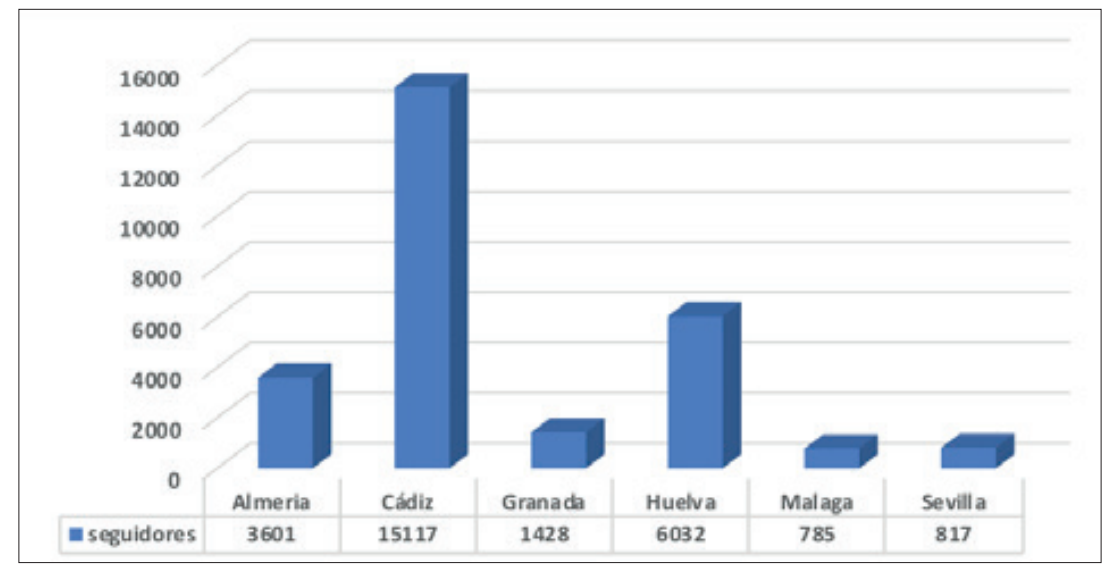

Fuente: Elaboración propia.

Respecto a las publicaciones de nuevo destaca Cádiz con más de 214 durante el periodo de estudio, le sigue Huelva con 137, Sevilla con 53 y Almería con 38. Granada solo ha tenido 3 publicaciones y ninguna Málaga (gráfico 18). 


\section{Gráfico 18: Número de publicaciones en Instagram por cada provincia andaluza}

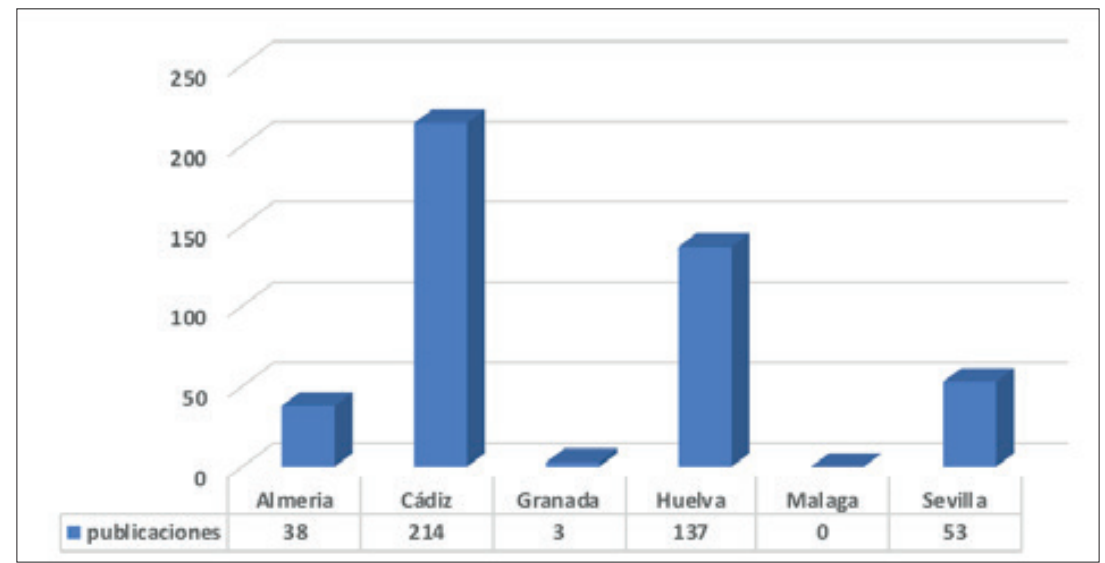

Fuente: Elaboración propia.

Como se ha comentado anteriormente, es en el engagement donde más destaca la red social de Instagram. Así, la provincia que ha generado mayores interacciones por cada publicación ha sido con diferencia Cádiz con 503,31, a más distancia se encuentran tanto Huelva como Almería con 206 y 178 respectivamente. Con bastante menos interacciones se encuentran Granada y Sevilla con 49 y 34 (gráfico 19).

\section{Gráfico 19. Número de interacciones por publicación en Instagarm por cada provincia andaluza}

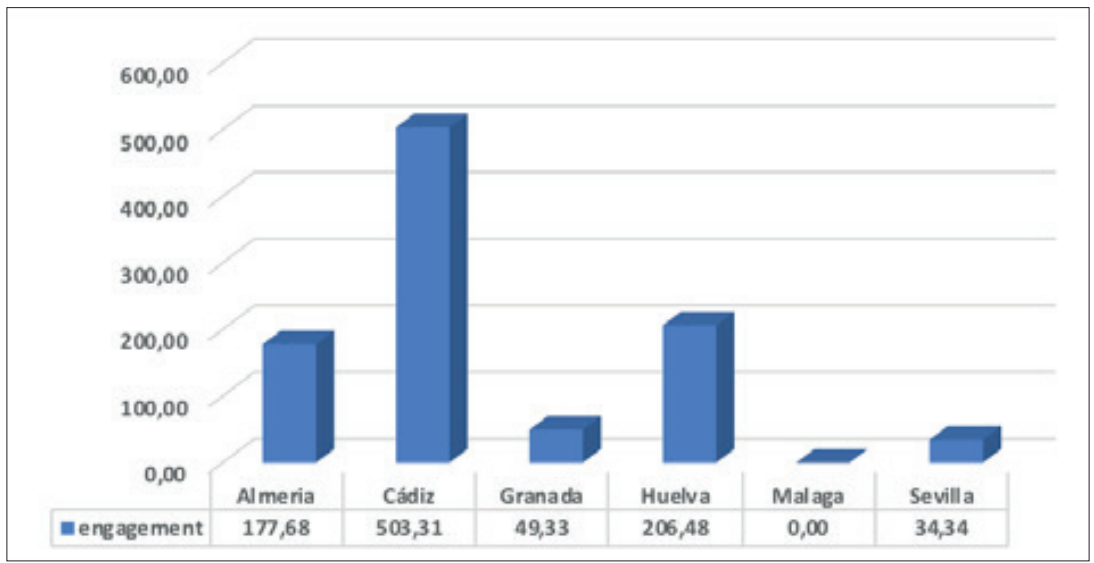

Fuente: Elaboración propia.

\section{Conclusiones y discusión.}

Nos encontramos en un momento en el ámbito empresarial en el que las redes sociales se consideran como un elemento imprescindible para emitir mensajes a nuestro público objetivo y lograr así una mayor cobertura y un mayor impacto en nuestras comunicaciones. A través del uso de las redes sociales las organizaciones podrán crear una comunidad en torno a la marca e incentivar una comunicación más 
interactiva con los usuarios. Las utilidades del empleo de estas redes sociales por las organizaciones son conseguir usuarios más identificados con la marca y con un mayor compromiso o vinculación emocional con la misma. Por esto mismo, las redes sociales se consideran como un medio ideal para la promoción turística, ya que los turistas son propensos a comentar sus experiencias de viaje en estos medios y recurrir a ellos para buscar opiniones de otros turistas, las cuáles serán tenidas muy en cuenta a la hora de tomar una decisión en el destino del viaje.

En el estudio se ha podido comprobar que las redes sociales con mayor número de usuarios es Facebook, aunque no a mucha distancia se encuentra Twitter, teniendo también muy en cuenta Instagram que aún no ha llegado a alcanzar el número de usuarios de las dos anteriores. Respecto a la intervención de las provincias andaluzas en dichas redes en el número de publicaciones los resultados son muy parecidos al número de usuarios siendo de nuevo Facebook la red social en la que se realiza más mensajes, pero esta vez a menor distancia respecto a Instagram y Youtube. Por lo tanto, destacar a Facebook como principal red social de promoción turística de las provincias de Andalucía, teniendo en cuenta que las demás redes sociales también tienen cierto protagonismo teniendo un buen número de seguidores y realizando un buen número de publicaciones.

Para conocer las interacciones que generan los perfiles de las redes sociales se ha tenido en cuenta la variable de engagement o compromiso. Una vez obtenido los datos en los 6 meses de estudio caben destacar a Instagram y Facebook con muchísima diferencia respecto las demás. Por lo tanto, se estableces como plataformas ideales para generar compromiso o engagement entre los usuarios en la información turística. Caso destacado es el de Instagram que pese a no ser la que tiene mayor número de seguidores y más publicaciones se convierte en una red social donde los usuarios son muy activos interviniendo en el contenido. En este mismo sentido destacar también el escaso engagement producido en Twitter, lo que la convierte en una plataforma más de carácter informativo. Por último, aunque la actividad y el engagement en Youtube no es alto permite dar a conocer visualmente los destinos turísticos.

En lo que respecta a los tipos de publicaciones destacan con mucha diferencia el contenido de imágenes, siendo la más utilizada en todas las redes sociales analizadas (excepto Youtube que solo permite videos). Por último, destacar que las publicaciones de videos en Facebook son las que mayor interacción o engagement poseen, por lo tanto, aunque la actividad de los videos en Youtube y en las demás redes social no es el más alto sí permite llamar la atención y conseguir una alta interacción permitiendo dar a conocer visualmente los destinos turísticos, por lo que se considera un tipo de contenido interesante de mostrar a los usuarios.

En la literatura se han realizado varios artículos que miden la presencia y actividad de las redes sociales en el sector turístico. Al igual que en el presente estudio Huertas et al. (2015) sobre la utilización de las redes sociales en algunas provincias destacan la importancia de las publicaciones de imágenes y videos como principales generadores de engagement o interacción de los usuarios, aunque en el estudio se especifica que se utiliza poco ese tipo de publicaciones, al contrario de este estudio que son bastante utilizadas. Sin embargo, destaca a Twitter como red social con mayor engagement que Facebook, todo lo contrario que en el presente estudio, lo que puede considerarse que en estos dos o tres últimos años dichas redes sociales hayan evolucionado en su manera de dirigirse a los usuarios en las redes sociales. Al igual que este estudio en la investigación de Mendes Thomaz et al. (2013) también resalta la importancia de las instituciones públicas para la promoción de los destinos turísticos y el desarrollo e implementación de estrategias en las redes sociales. De esta forma, también se destaca que las redes sociales son idóneas para el marketing de relaciones y que además pueden ser utilizados tanto como canal de información como para compartir experiencias, información, consejos, ofertas y soporte a los turistas, conectando a éstos con los gestores turísticos de las organizaciones. En los estudios de Giraldo y María Dolores (2017) y Sánchez y Giraldo (2015) en el que también utilizan el modelo PRGS para la obtención de métricas para analizar las comunidades autónomas como destino turístico llegan a conclusiones similares a este estudio en el sentido de que las redes sociales medido a través de la participación del usuario, no solo depende del número de seguidores, sino que depende en gran medida del contenido que se genere por parte de la propia marca, el tipo y la calidad del contenido publicado. Así, esto influirá en la decisión de compra de aquellos turistas potenciales que estén planificando sus vacaciones y se les ofrezca una variada y atractiva información de la oferta turística a través de las redes sociales.

En comparación con otros estudios del sector turístico como los de Martínez et al. (2013), Cuadra et al. (2014) y Morales et al. (2014) en términos generales se observa una mayor utilización de las redes sociales en este estudio respecto a los anteriormente comentados. En sentido, podemos considerar que el uso de las redes sociales en el sector turístico ha ido cobrando mayor importancia a lo largo de estos últimos años 
Sobre las limitaciones y posibles futuras líneas de investigación cabe destacar que, aunque la metodología es idónea para la propuesta de obtención del ROI en las redes sociales mediante la medición de diversos indicadores de rendimiento, no se podría emplear para conocer otra información de interés como por ejemplo qué tipo de actividad o de interacciones se realiza en las redes sociales. Así, sería interesante como futuras líneas de investigación realizar un análisis de contenido para analizar las publicaciones y las interacciones que se realizan en las redes sociales del sector turístico a través de un software de investigación cualitativa como Atlas o Nvivo.

\section{Bibliografía}

Amboage, S. E.

2015. La promoción de destinos turísticos termales a través de los medios sociales: análisis del caso de los balnearios de Galicia y del norte de Portugal (tesis doctoral). Universidad de La Coruña, España. Bilgihan, A., Barreda, A., Okumus, F. y Nusair, K.

2016. "Consumer perception of knowledge-sharing in travel-related online social networks". Tourism Management, 52: 287-296.

Blanchard, O.

2012. El retorno de la inversión en Social Media. Anaya Multimedia. Madrid.

Bonilla, J.

2013. "Nuevas tendencias del turismo y las tecnologías de información y las comunicaciones". Turismo y Sociedad, 14: 33-45.

Bragg, S. M.

2012. Business ratios and formulas: a comprehensive guide. John Wiley \& Sons. United States of America. Buhalis, D.

1998. "Strategic uses of information technologies in the tourism industry". Tourism Management, 19(5): 409-421.

Buhalis, D. y Law, R.

2008. "Progress in information technology and tourism management: 20 years on and 10 years after the internet - the state of eTourism research". Tourism Management, 29(4): 609-623.

Buhalis, D. y Mamalakis, E.

2015. "Social media return on investment and performance evaluation in the hotel industry context". In Information and Communication Technologies in Tourism, (241-253).

Caro, J. L., Luque, A. y Zayas, B.

2015. "Nuevas tecnologías para la interpretación y promoción de los recursos turísticos culturales". Pasos. Revista de Turismo y Patrimonio Cultural, 13(4): 931-945.

Casaló, L. V., Flavián, C., y Guinalíu, M.

2010. "Relationship quality, community promotion and brand loyalty in virtual communities: Evidence from free software communities". International journal of information management, 30(4): 357-367. Castelló Martínez, A.

2012. Del ROI al IOR: el retorno de la inversión de la comunicación empresarial y publicitaria en medios sociales. Introducción a la Investigación de Medios Publicitarios. Recuperado el 18 de abril de 2017 en: https://rua.ua.es/dspace/bitstream/10045/20513/1/25.pdf

Cosenza, V.

2012. Social media ROI. Apogeo Editore. Milán.

Chung, J. Y. y Buhalis, D.

2008. "Information needs in online social networks". Information Technology \& Tourism, 10(4): 267-281. Cuadra, S. M., Morales, P. C. y Agüera, F. O.

2014. "Reputación online, redes sociales y turismo. un estudio de caso en Andalucía". TURyDES, 7(16): 1-17.

Domínguez Vila, T. y Araujo Vila, N.

2012. "El fenómeno 2.0 en el sector turístico. El caso de Madrid 2.0". Pasos. Revista de Turismo y Patrimonio Cultural, 10(3): 225-237.

Ferrá, F. C. M. y Cardona, J. R.

2015. "Presencia de las cadenas hoteleras españolas en los medios sociales". CULTUR-Revista de Cultura e Turismo, 9(1): 05-35. 
Fisher, T.

2009. "ROI in social media: A look at the arguments". Journal of Database Marketing \& Customer Strategy Management, 16(3): 189-195.

Galí, N., Majó, J. y Vidal, D.

2000. "Patrimonio Cultural y Turismo: Nuevos modelos de promoción vía internet". Cuadernos de Turismo, (6): 73-87.

Geho, P. R. y Dangelo, J.

2012. "The evolution of social media as a marketing tool for entrepreneurs". The Entrepreneurial Executive, 17: 61-68.

Geho, P. R., Smith, S. y Lewis, S. D.

2011. "Is Twitter a viable commercial use platform for small businesses? An empirical study targeting two audiences in the small business community". The Entrepreneurial Executive, 15: 73.

Giraldo Cardona, C. M. y María-Dolores, S. M. M.

2017. "Análisis de la actividad y presencia en facebook y otras redes sociales de los portales turísticos de las Comunidades Autónomas españolas". Cuadernos de Turismo, (39): 239-264.

González Fernández-Villavicencio, N. G.

2016. "Bibliotecas, medios y métricas de la web social". Anales de Documentación, 19(1): 1-13.

Gretzel, U. y Yoo, K. H.

2013. "Premises and promises of social media marketing in tourism". The Routledge handbook of tourism marketing, 491-504.

Hernández Estárico. E., Fuentes Medina, M. L. y Morini Marrero, S.

2012. "Una aproximación a la reputación online de los establecimientos hoteleros españoles". Papers de turismo, 52: 63-88.

Hudson, S. y Thal, K.

2013. "The impact of social media on the consumer decision process: Implications for tourism marketing". Journal of Travel \& Tourism Marketing, 30(1-2): 156-160.

Huertas, A. y Marine-Roig, E.

2016. "User reactions to destination brand contents in social media". Information Technology \& Tourism, 15(4): 291-315.

Huertas, A., Setó-Pàmies, D. y Míguez-González, M. I.

2015. "Comunicación de destinos turísticos a través de los medios sociales". El profesional de la información, 24(1).

Inversini, A., Marchiori, E., Dedekind, C. y Cantoni, L.

2010. "Applying a conceptual framework to analyze online reputation of tourism destinations". Information and communication technologies in tourism, 321-332.

Jayasingh, S. y Venkatesh, R.

2015. "Customer engagement factors in facebook brand pages". Asian Social Science, 11(26): 19.

Kang, M. y Schuett, M. A.

2013. "Determinants of sharing travel experiences in social media". Journal of Travel \& Tourism Marketing, 30(1-2): 93-107.

Kingma, B., y McClure, K.

2015. "Lib-value: Values, outcomes, and return on investment of academic libraries, phase III: ROI of the Syracuse University Library". College \& Research Libraries, 76(1): 63-80.

Law, R., Buhalis, D. y Cobanoglu, C.

2014. "Progress on information and communication technologies in hospitality and tourism". International Journal of Contemporary Hospitality Management, 26(5): 727-750.

Leeflang, P. S., Verhoef, P. C., Dahlström, P. y Freundt, T.

2014. "Challenges and solutions for marketing in a digital era". European management journal, 32(1): 1-12.

Leung, D., Law, R., Van Hoof, H. y Buhalis, D.

2013. "Social media in tourism and hospitality: A literature review". Journal of Travel \& Tourism Marketing, 30(1-2): 3-22.

Lim, W.

2010. The Effects of social media networks in the hospitality industry. University of Nevada, Las Vegas. Professional paper. Recuperado el 8 de diciembre de 2017 en: http://digitalcommons.library.unlv.edu/ thesesdissertations/693.

Lincoln, S.R.

2009. Mastering Web 2.0. Kogan Page. London. 
Litvin, S. W., Goldsmith, R. E., y Pan, B.

2008. "Electronic word-of-mouth in hospitality and tourism management". Tourism Management, 29(3): 458-468.

Liu, Z. y Park, S.

2015. "What makes a useful online review? Implication for travel product websites". Tourism Management, 47: 140-151.

Lloret Romero, N.

2011. "ROI. Measuring the social media return on investment in a library". The Bottom Line, 24(2): 145-151.

López, E.

2010. La reputación corporativa online aplicada al sector turístico en España. IV Congreso Cibersociedad, Málaga, 12-29.

Luque-Martínez, T., Alberto Castañeda-García, J., Frías-Jamilena, D. M., Muñoz-Leiva, F., y Rodríguez-Molina, M. A.

2007. "Determinants of the use of the internet as a tourist information source". The Service Industries Journal, 27(7): 881-891.

Mangold, W. y Faulds, D.

2009. "Social media: The new hybrid element of the promotion mix". Business Horizons, 52(4), 357-365.

Márquez-Domínguez, C., López-López, P. C. y Arias, T. E.

2017. Social networking and political agenda: Donald trump's Twitter accounts. In Information Systems and Technologies (CISTI), 12th Iberian Conference, Lisboa, 1-6.

Martínez-Fernández, V. A., Juanatey-Boga, Ó., Crespo-Pereira, V. y Burneo, M. D. M.

2015. "Prensa nativa digital y redes sociales: cibermedios en Facebook y Twitter". International Journal of Information Systems and Software Engineering for Big Companies (IJISEBC), 2(2): 42-50.

Martínez, A. C.

2010. “Cuánto vale un fan? El reto de la medición de la audiencia en los social media”. Pensar la publicidad, 4(2): 89.

Martínez, S. M, Bernal García, J. J., y Mellinas, J. P.

2013. "Análisis del nivel de presencia de los establecimientos hoteleros de la Región de Murcia en la Web 2.0". Cuadernos de Turismo, (31): 245-261.

Martínez, S. M., Bernal García, J. J. y Mellinas, J. P.

2012. "Los hoteles de la región de Murcia ante las redes sociales y la reputación online'. Revista de análisis turístico, (13): 1-10.

McMullen, A.

2013. "The value of values". The Bottom Line, 26(1): 4-6.

Mendes Thomaz, G., Biz, A. A. y Gândara, J. M. G.

2013. "Innovación en la promoción turística en medios y redes sociales: Un estudio comparativo entre destinos turísticos". Estudios y perspectivas en turismo, 22(1): 102-119.

Morales, P. C., Orgaz Agüera, F. y Moral Cuadra, S.

2014. Web 2.0 y turismo. Un estudio de caso en hoteles de Córdoba. Cultura, desarrollo y nuevas tecnologías: VII jornadas de investigación en turismo, Córdoba, 335-356.

Munar, A. M.

2012. "Social media strategies and destination management". Scandinavian Journal of Hospitality and Tourism, 12(2): 101-120.

Murgui, L. M.

2011. "El impacto de las redes sociales en las empresas españolas". Studia Europaea Gnesnensia, (3), 37-53.

Oviedo-García, M., Muñoz-Expósito, M., Castellanos-Verdugo, M. y Sancho-Mejías, M.

2014. "Metric proposal for customer engagement in Facebook". Journal of Research in Interactive Marketing, 8(4): 327-344.

Öz, M.

2015. "Social media utilization of tourists for travel-related purposes". International Journal of Contemporary Hospitality Management, 27(5): 1003-1023.

Perdomo Castellano, L. A., Rincón Mármol, R. A. y Sánchez, M. G.

2014. "Desafíos del marketing turístico en el entorno 2.0 challenges of the tourist marketing in the environment 2.0". Marketing Visionario, 2(2): 125-141. 
Powell, G., Groves, S., y Dimos, J.

2011. ROI of Social Media: How to improve the return on your social marketing investment. John Wiley \& Sons. United States of America.

Ruzic, D. y Bilos, A.

2010. Social media in destination marketing organisations (DMOs). Tourism and Hospitality Management, Conference proceedings, Croacia, $178-190$.

Sánchez Casado, N. y Giraldo Cardona, C. M.

2015. "Análisis de la actividad en redes sociales de marcas del sector moda como herramienta de social commerce". Anuario de Jóvenes Investigadores, (8): 72-74.

Schmidt, M.

2014. Return on Investment ROI Explained: Definition, Meaning, and Example Calculations. Business Encyclopaedia. Recuperado el 22 de febrero de 2015 en: https://www.business-case-analysis.com/ return-on-investment.html

Senecal, S. y Nantel, J.

2004. "The influence of online product recommendations on consumers' online choices". Journal of retailing, 80(2): 159-169.

Sigala, M.

2007. Web 2.0 in the tourism industry: A new tourism generation and new ebusiness models. Recuperado el 27 de octubre de 2017 en: http://www.traveldailynews.com/pages/show_page/20554

Sirakaya, E. y A. Woodside

2005. "Building and testing theories of decision making by travelers". Tourism Management, 26(6): 815-832.

Sobejano, J. y Cavalcanti, J.

2011. Social Media IOR: Las Relaciones como moneda de rentabilidad. Bubuk Publishing. Madrid.

Sotiriadis, M. D. y Van Zyl, C.

2013. "Electronic word-of-mouth and online reviews in tourism services: the use of twitter by tourists". Electronic Commerce Research, 13(1): 103-124.

Stockdale, R., Ahmed, A. y Scheepers, H.

2012. Identifying business value from the use of social media: an SME perspective, Proceedings of IS Innovation in Pacific Asia, PACIS, 11-15.

Taladriz-Mas, M.

2013. "Los servicios de información y el retorno de la inversión: cómo llegar a conocerlo". El profesional de la información, 22(4).

Tessler, A.

2013. Economic valuation of the British Library. Oxford Economics. Oxford.

Thevenot, G.

2007. "Blogging as a social media". Tourism and Hospitality Research, 7(3-4): 287-289.

Werthner, H., Alzua-Sorzabal, A., Cantoni, L., Dickinger, A., Gretzel, U., Jannach, D. y Stangl, B.

2015. "Future research issues in IT and tourism". Information Technology \& Tourism, 15(1): 1-15.

Wöber, K., y GretzeL, U.

2000. "Tourism manager's adoption of marketing decision support systems". Journal of Travel Research, 39(2): 172-181.

Wozniak, T., Stangl, B., Schegg, R., y Liebrich, A.

2017. "The return on tourism organizations' social media investments: Preliminary evidence from belgium, france, and Switzerland". Information Technology \& Tourism, 17(1): 75-100.

Xiang, Z., y Gretzel, U.

2010. "Role of Social Media in Online Travel Information Search". Tourism Management, 31(2), 179-188.

Zeng, B. y Gerritsen, R.

2014. "What do we know about social media in tourism? A review". Tourism Management Perspectives, 10: $27-36$.

Recibido: 